\title{
Cool Parent Syndrome; Redefining Cool
}

\section{Ganesh Amgain}

Authors Info:

\section{Ganesh Amgain}

Editor, Europasian Journal of Medical Sciences (EJMS);

Psychological Counselor, Nirvana Psychosocial Care Center \& Research Institute, Sankhamul, New-Baneshwor, Kathmandu, Nepal

Correspondence: ganeshamgain@gmail.com Contact: +977-9849081162

\section{Disclaimer:}

Conflict of Interest: None Source of Support: None Copyright (C) 2019 by author(s), licensed under the Creative Commons Attribution International License 4.0.

\section{ABSTRACT:}

Parenting style also called parental behaviour is the way parents generally relate to their children. It is the overall emotional climate in which parents raise their children. It has been divided into four different categories; Authoritative, Authoritarian, Permissive and Uninvolved. Experts recommend parents to follow authoritative parenting styles which is perceived to be the most effective one. But in Nepalese context authoritarian parenting style runs among the families. Researches has shown that Nepalese parenting style could not be incorporated into a single parenting style as suggested by Baumrind. Present day's parents in Nepalese context, not setting clear rules for the children, and provision of more than enough freedom, is found to be cool. Most of the parenting studies only find the correlation between the parenting styles and outcomes rather than cause and effect. That's why, rather than sticking to specific type of parenting style or be cool with them, it's crucial to take time and be able to connect to them and address the needs of the children. Keywords: Parenting styles, Cool Parents, Cool Parent Syndrome.
Article Info

Received: October 26, 2019

Accepted: November 18, 2019

Published online: December 15, 2019

How to cite this article in Vancouver Style?

Amgain G. Cool Parent Syndrome: Refining

Cool. Europasian J Med Sci 2019; 1(1):1-4.

https://doi.org/10.46405/ejms.v1i1.12
Access this article online

Publisher Note:

The Europasian Journal of Medical Sciences (EJMS) is an official Journal of Nirvana Psychosocial Care Center \& Ressearch Institute www.nirvanapscc.com. The Journal as well as publisher remain neutral with regards to any jurisdictional claims in any published articles, its contents and the institutional affiliations of the authors.
Quick Response (QR) Code

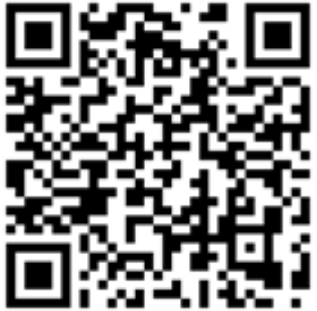

Scan Me for Full Text 


\section{INTRODUCTION}

$\int$ ournaling on some psycho-social issues that I usually face in my private practice, I have had the nostalgia trip of the workshop 'Joyful Parenting'. It reminds me of the maxim 'Home is the first school of the children, parents being the first teachers' which is uncommon to hear people say this. Being the parents is indeed the joyful blessing in itself that poses handful of responsibilities and challenges and risks of breaching the boundaries and harming the children in nominal cause of educating them, setting goals for them and setting up a culture of positive discipline. John Wilmot mentions in her quote, 'Before I got married, I had six theories about bringing up children; now I have six children, and no theories. This makes sense that there is nothing as such like perfect parents, it's just about being genuine one. So, being the parent is the work in progress irrespective of the parenting styles.

\section{Parenting Style}

Developmental psychologist Diana Blumeberg Baumrind has identified three main parenting styles in early child development: authoritative, authoritarian, and permissive and uninvolved parenting is added later on to her theory. Authoritative parents have high expectations for achievement and maturity, but they are also democratic, warm, affectionate and responsive. ${ }^{1}$ They are open about setting rules and enforcing boundaries. Children of these parents appear happy, competent social skills, more independent, have higher academic success and better mental health. Authoritarian parents are unresponsive and less nurturing. They use stern discipline and often employ punishment to control children's behaviour and demand blind obedience. Children of these parents are usually less independent, insecure and have low selfesteem, exhibit more behavioural problems and are more prone to mental health issues. ${ }^{2}$

Permissive parents are warm and indulgent. They do not like to say no or disappoint their children. They set very few rules and boundaries and they are reluctant to enforce rules. Children raised with this parenting style tend to be impulsive, rebellious, aimless, domineering, aggressive and low in self-reliance, self-control and achievement ${ }^{3}$. Uninvolved parents are indifferent and don't set firm boundaries or high standards. They tend to have mental health issues themselves like maternal depression, physical abuse or child neglect when they were kids. Children of these parents are more impulsive and have low self-regulation. They encounter more mental health issues like addiction, suicidal thoughts and delinquent behavior.

Followed by this classification certain parenting styles are soughed after their significance despite the fact that has to be the indicative of the emotional climate in the home. ${ }^{4}$ These parenting styles don't exist singly rather they are the amalgamation of acceptance, responsiveness, demand and control. Research suggest that authoritative parenting is positively correlated to mental health and satisfaction with life, on the contrary authoritarian is associated negatively to these variables 5 .

\section{Parenting in Nepalese Context}

Parenting mostly depends on individual traits and skills, culture and values, social status and family dynamics. ${ }^{6}$ Bornstein et al. mentions, parenting and cultures are intertwined with each other. ${ }^{7}$ The parenting styles and values for parents from Asian countries are deep rooted in their culture of collectivism where people are integrated in strong and cohesive groups which protect them throughout their life in exchange for unquestioning loyalty. ${ }^{8}$ Among the Nepalese parents, most widely prevalent parenting style is authoritarian at the same time parents use their power to control the children's behaviour. It is usually seen disrespectful to reason question or argue. On the contrary, mostly children who belong to low social economic status survive uninvolved parenting.

Among the Nepalese highly educated and modern parents, with this borrowed concepts of the parenting, parenting has been more cosmetic rather than congruent. Nepalese parents especially the ones from urban and cities, have the need to confirm being the cool parents among other. ${ }^{2}$ Surviving the authoritarian parenting or not being able to get whatever child lack, today's/modern parents are obsessed to offer their introjects to children what they wished to for themselves during their childhood. Researches in Nepalese parenting shows significant statistical association between parents spending quality time with children and children behaviours like, trouble in sleeping, poor appetite, sad/unhappy, prefer playing/ being alone rather than with peers, lack of confidence in his/her abilities, shy, sensitive to criticism, often fails to finish things, poor concentration and attention in school task ${ }^{9}$. 


\section{OPEN ACCESS \\ https://doi.org/10.46405/ejms.v1i1.12}

Amgain G. Cool Parent Syndrome ...

As Wayne Dyer says, 'Our children are not ourchildren, rather they come through us, but they are life itself, wanting to express itself.' The problem here among the ultramodern aware parents is that they impose the projection of their own inner child of how they should be treated. Parents with such need of being cool enough with their children tend to be more permissive. They fail to set firm limits, to monitor children's activities closely. Competition trip of not questioning the children about their actions, underage drinking parties, practicing freedom and leniency, provision of cool tech gadgets, and choice of substance they use and many more is profoundly cool among some parents group. Likewise, party culture that is flourishing recently with no curfews in home concerning the returns is the coolest among the teens about their parents. This parenting style is associated with greater academic entitlement and, in turn, to more perceived stress and poorer mental health ${ }^{10}$.

\section{REDEFINING COOL}

$\mathrm{H}$ aving worked as a counsellor for few years on different issues of the adolescents, young adults and parents, I can now imagine the envy that the Nepali children of over protecting parents have over children of cool parents. As parents demand to listen every single small things about their child with the belief that they would be able to tell bigger things that happens in their lives tomorrow. Demanding children to share everything in a way is violating a child's space as individual entity termed as 'Boundary' that varies with individual. This reminds me of one of my adolescent client who would share his trauma of his father asking him to watch adult entertainment in the name of sex education. Same is the case with experimenting smoking marijuana to doing wide ranges of other drugs. More than parenting styles, association with deviant peers, delinquent behaviour, provision of alcohol by parents, and previous use of other substances were associated with substance use. ${ }^{11}$ A national poll by the University of Michigan's C.S. Mott Children's Hospital shows that while parents accurately estimate the rate of substance abuse among other teens, where as they remain blissfully ignorant of their own children's drug use. As parents, it's utmost to look for the behavioural alerts of children rather than merely acting cool and turning a blind eye towards their responsibilities.

More than being in power trip of cool parenting, bringing responsible parenting back and redefining cool is crucial. Specific behaviour - parenting practice is pivotal in raising the children. 5 Rather than being cool and bearing the cost of addiction, distorted selfimage of children, insecure attachment with people, higher perceived stress, it's high time for parents to be aware of the competence and skills: Parent-child relationship skills, encouraging desirable behaviour, managing misbehaviour, self-regulation skills, coping skills, partner support skills and many more which would help children to be more humane. ${ }^{12}$ While redefining cool, it is important to be involved, nurturing, responsive, and supportive, yet set firm limits for the children and having zero tolerance policy in the family is more like the another wheel. It is vital to listen to the child's viewpoint, acknowledge it but not always accept it. Doing so, parents teach them selfregulation skills and make them capable of responding.

\section{REFERENCES}

1. Baumrind, D. Child-care practices anteceding three patterns of preschool behaviour. Genetic Psychology Monographs 1967;75:43-88. Google Scholar | Full Text

2. Dangol, A. Parenting among Nepalese families in Lisbon and its effect on child integration. Lisboa: ISCTEIUL, 2015. Google Scholar I Full Text

3. American Psychological Association, 2016. Full Text

4. Sepra, C. A review of the relationship among parenting practices, parenting styles, and adolescent school achievement'. Educational Psychology Review. 2000;17(2):125-46.https://doi.org/10.1007/s10648005-3950-1 Google Scholar 1 CrossRef $\mid$ Full Text

5. Rubin M, Kelly BM. A cross-sectional investigation of parenting style and friendship as mediators of the relation between social class and mental health in a university community. International journal for equity in health 2015;14(1):87.https://doi.org/10.1186/ s12939-015-0227-2 Google Scholar | CrossRef | PMC Full Text

6. Selin H. Parenting across cultures: Childrearing, motherhood and fatherhood in non-western cultures. Dordrecht: Springer Netherlands 2014.https://doi. org/10.1007/978-94-007-7503-9 Google Scholar | CrossRef I Full Text

7. Bornstein $\mathrm{MH}$, Putnick DL, Lansford JE. Parenting attributions and attitudes in cross-cultural perspective. Parenting: Science and Practice 2001;11:214-237. https://doi.org/10.1080/15295192.2011.585568 Google Scholar $\mid$ PMC I CrossRef 
8. Hofstede G. Culture's consequences: Comparing values, behaviours, institutions and organizations across nations. Thousand Oaks, CA: Sage. 2001. Google $\underline{\text { Scholar | Full Text }}$

9. Hossain S, Huq Adhikari B, Eusuf Zai S, Haque Tanjilul S. Parenting skills and child behavior: A crosssectional study in some selected areas of Nepal. South East Asia journal of Public Health 2015;5:44-48. https://doi.org/10.3329/seajph.v5i1.24851 Google Scholar I CrossRef | Full Text

10. Barton AL, Hirsch JK. Permissive parenting and mental health in college students: Mediating effects of academic entitlement. Journal of American college health 2016;2(64):1-8. https://doi.org/10.1080/07448 $\underline{481.2015 .1060597}$ Google Scholar I PMC I CrossRef I Full Text
11. Berge J, Sundell K, Öjehagen A,Hakasson A, Role of parenting styles in adolescent substance use: results from a Swedish longitudinal cohort study. BMJ 2016; 4:6(1). https://doi.org/10.1136/ bmjopen-2015-008979 Google Scholar | PMC | CrossRef | Full Text

12. Sanders Matthew R. 'Triple P-Positive Parenting Program as a public health approach to strengthening parenting'. Journal of Family Psychology 2008;22(4): 506-17.https://doi.org/10.1037/0893-3200.22.3.506 Google Scholar | PMC | CrossRef | Full Text 